\title{
Diabetes and elevated urea level predict for uretero-ileal stricture after radical cystectomy and ileal conduit formation
}

\author{
Nathan Hoag, MD; Nathan Papa, MD; Bhawanie Koonj Beharry, MD; Nathan Lawrentschuk, MD; \\ Danny Chiu, MD; Shomik Sengupta, MD; Damien Bolton, MD
}

Department of Urology, Austin Hospital, University of Melbourne, Australia

Cite as: Can Urol Assoc J 2017;11 (3-4):E88-92. http://dx.doi.org/10.5489/cuai.3848

Published online March 16, 2017

\section{Abstract}

Introduction: Benign uretero-ileal anastomotic stricture is a significant complication following radical cystectomy and ileal conduit urinary diversion after radical cystectomy. We examined risk factors for stricture formation to predict those at greatest stricture risk.

Methods: A retrospective chart review was conducted for patients undergoing radical cystectomy and ileal conduit diversion between 2002 and 2012. Demographic data and patient variables were analyzed to determine risk factors for uretero-ileal stricture using multivariate logistic regression.

Results: Over the study period, 133 patients underwent cystectomy and ileal conduit formation, with 14 (10.5\%) developing ureteroileal anastomotic stricture. Diabetes and elevated serum urea level (defined as $>7.1 \mathrm{mmol} / \mathrm{L}$ ) were associated with increased risk for development of uretero-ileal stricture (odds ratio 4.31 and 4.28, respectively; $p<0.05$ for each).

Conclusions: In this patient cohort, diabetes and elevated serum urea level were predictive for the development of uretero-ileal anastomotic stricture. Further prospective study with larger patient samples is required.

\section{Introduction}

Radical cystectomy with ileal conduit urinary diversion is a standard treatment of invasive bladder cancer, but is associated with a high rate of complications. ${ }^{1}$ Strictures of the ureteroileal anastomosis represent a significant complication following ileal conduit diversion, which often require intervention ${ }^{2}$ to prevent potential sequelae, including hydronephrosis, urinary obstruction, infection, renal failure, and formation of stones. ${ }^{3}$ The published rate of uretero-ileal anastomotic stricture after urinary diversion in the literature varies from $1.3-13 \%{ }^{4-10}$

Though exact reasons for the development of uretero-ileal anastomotic stricture remain to be elucidated, it is thought to be due to an inflammatory or ischemic etiology. ${ }^{6}$ It has been proposed that in most, the cause is likely multifactorial. ${ }^{11}$ Ways to minimize ischemic damage to the distal ureter include meticulous tissue-handling, avoidance of unnecessary dissection, and ensuring the distal ureter is viable before implanting into urinary diversion. ${ }^{6}$ Uretero-ileal anastomotic stricture can prove challenging to treat, with open revision often required to successfully manage this problem. ${ }^{12}$

The aim of this study was to review our experience with radical cystectomy and ileal conduit diversion to interrogate risk factors for uretero-ileal anastomotic stricture. This may assist in assigning a relative risk for future development of uretero-ileal anastomotic stricture.

\section{Methods}

A retrospective chart review was conducted to identify all patients who had undergone radical cystectomy and ileal conduit urinary diversion for bladder cancer at three hospitals (one public, two private) in Melbourne, Australia, between 2002 and 2012. Institutional ethics board approval was obtained (LNR/15/Austin/399). Patient records were reviewed to capture demographic data, including gender, age, body mass index, medical comorbidities, prior chemotherapy, and smoking history. Preoperative data was also collected, including hemoglobin level, serum urea and creatinine, and albumin level. Intraoperative and postoperative data recorded included length of surgery, use of inotropes, requirement of blood transfusion, sepsis, and evidence of anastomotic urine leak. Development of uretero-ileal anastomotic stricture was considered to have occurred if there was confirmatory radiologic or endoscopic evidence. Routine imaging was obtained at approximately three months postoperatively and at least annually thereafter. Imaging was also performed for symptoms of urinary tract obstruction or evidence of renal function deterioration.

The recorded variables were assessed for association with uretero-ileal anastomotic stricture using univariable logistic 
regression analysis, with stricture as the outcome of interest. Laboratory values were dichotomized as normal and above normal levels, as per reported reference ranges, and analyzed as binary variables. Diabetics were not stratified according to glycemic control. Elevated blood urea was defined as greater than $7.1 \mathrm{mmol} / \mathrm{L}$, elevated creatinine as greater than $106 \mu \mathrm{mol} / \mathrm{L}$, and hemoglobin was divided at the median of 134 g/L. American Society of Anesthesiologists (ASA) score was analyzed separately using the Fisher's exact test due to its categorical nature. The variables that attained significance set at the 0.05 level on univariable analysis, diabetic and elevated serum urea level, were entered into a multivariable logistic model with an interaction term to ascertain whether they retained significance. Inclusion of further predictors was not done due to the risk of over-fitting. An additive index was created from these two variables and a trend for increasing proportion of stricture was examined with Cuzick's non-parametric test. Urea level was subsequently examined as a continuous variable alone in a logistic model in order to obtain probabilities of stricture formation at particular serum levels. Analysis was performed using Stata SE v.12.0 (College Station, TX, U.S.) with significance set at 0.05 .

\section{Results}

A total of 133 patients were identified in this series having undergone radical cystectomy and ileal conduit formation. Fourteen patients $(10.5 \%)$ developed uretero-ileal anastomotic stricture. Demographic information and clinical data collected is summarized in Tables 1 and 2 .

Of 133 patients, median age was 70 years, with 98 $(73.7 \%)$ males. Thirty $(22.6 \%)$ patients were diabetic and mean serum urea level was 6.2 (range 1.3-15). Variable distribution by stricture vs. no stricture and $p$ values from univariable logistic regression analysis of association between variable and stricture is shown in Table 3.

The predicted probability of stricture for a urea level of $4.0 \mathrm{mmol} / \mathrm{L}$ was $6 \%$ (95\% confidence interval $[\mathrm{Cl}] 0-11 \%)$, rising to $13 \%(95 \% \mathrm{Cl} 7-20 \%)$ with a urea level of $8 \mathrm{mmol} / \mathrm{L}$ when examined as a continuous variable (Fig. 1).

The variables most strongly associated with uretero-ileal anastomotic stricture were diabetic patient and elevated serum urea level (defined as $>7.1 \mathrm{mmol} / \mathrm{L}$ ). These two variables were entered simultaneously into a multivariable logistic model where they both retained conventional significance (odds ratio [OR] 4.31 for diabetes; $p=0.016$; and OR 4.28 for elevated serum urea; $p=0.017$ ). An interaction term was included in the model, but its value did not reach significance $(p>0.1)$. The proportion of patients with stricture that had zero, one, or two of these risk factors is shown in Table 4.

There was a strong trend towards an increasing proportion of strictures as the number of risk factors a patient had increased $(p<0.001)$. Having at least one risk factor was strongly predictive of subsequent stricture development (OR 17.3; $p=0.007$ ) with associated sensitivity of $92.9 \%$ and specificity of $57.1 \%$.

\section{Discussion}

Prior research examining variables associated with increased risk of uretero-ileal anastomotic stricture determined those with a higher body mass index (BMI) were significantly more likely to develop stricture. ${ }^{7}$ A study by Richards et al showed that Clavien complication Grade 3 or greater and postoperative urine leak significantly predicted formation of uretero-ileal anastomotic stricture in the left and right ureter, respectively. ${ }^{11}$

Although the overall number of uretero-ileal strictures was low in our series, diabetic status and elevated serum urea level predicted for the development of stricture. This finding could fit with the theory that ischemic insult may predispose to stricture development, as those with the above risk factors may have impaired tissue-healing.

Large et al reported on their series comparing running vs. interrupted anastomosis on uretero-intestinal stricture rate, and found on multivariable analysis that postoperative urinary tract infection and a running anastomotic technique were associated with increused risk of stricture. ${ }^{6}$

Uretero-ileal anastomotic stricture tends to affect the left side more than the right, which is thought to be related to increased mobilization and tunneling under the sigmoid colon. ${ }^{2,6,7,13}$ Though anastomotic strictures may develop many years following urinary diversion, the mean time to stricture occurrence has been reported to be between five

Table 1. Summary of continuous variables collected

\begin{tabular}{|c|c|c|c|c|c|}
\hline Variable (\# pts. missing data) & Minimum & $25^{\text {th }}$ percentile & Median & $75^{\text {th }}$ percentile & Maximum \\
\hline Age & 35 & 61.1 & 70 & 76 & 85 \\
\hline Body mass index (8) & 14 & 24.3 & 28 & 30.5 & 41.7 \\
\hline Preoperative hemoglobin (4) & 88 & 125 & 134 & 147 & 191 \\
\hline Preoperative urea level (mmol/L) & 1.3 & 4.3 & 6.2 & 7.7 & 15 \\
\hline Preoperative creatinine (4) & 32 & 70 & 82 & 106 & 183 \\
\hline Preoperative albumin (11) & 14 & 27 & 34 & 38 & 65 \\
\hline Operative time (mins) (5) & 180 & 240 & 270 & 315 & 500 \\
\hline
\end{tabular}




\begin{tabular}{|c|c|}
\hline Variable & n (\%) \\
\hline \multicolumn{2}{|l|}{ Sex } \\
\hline Male & $98(73.7)$ \\
\hline Female & $35(26.3)$ \\
\hline \multicolumn{2}{|l|}{ Diabetic } \\
\hline Yes & $30(22.6)$ \\
\hline No & $103(77.4)$ \\
\hline \multicolumn{2}{|l|}{ Smoker } \\
\hline Yes & $85(63.9)$ \\
\hline No & $48(36.1)$ \\
\hline \multicolumn{2}{|c|}{ Preoperative urea } \\
\hline$>7.1 \mathrm{mmol} / \mathrm{L}$ & 45 (33.8) \\
\hline$\leq 7.1 \mathrm{mmol} / \mathrm{L}$ & $88(66.2)$ \\
\hline \multicolumn{2}{|c|}{ Preoperative creatinine* } \\
\hline$>106 \mu \mathrm{mol} / \mathrm{L}$ & $28(21.7)$ \\
\hline$\leq 106 \mu \mathrm{mol} / \mathrm{L}$ & $101(78.3)$ \\
\hline \multicolumn{2}{|c|}{ Preoperative hemoglobin* } \\
\hline$>134 \mathrm{~g} / \mathrm{L}$ & $61(47.3)$ \\
\hline$\leq 134 \mathrm{~g} / \mathrm{L}$ & $68(52.7)$ \\
\hline \multicolumn{2}{|l|}{ ASA score* } \\
\hline 1 & $5(4)$ \\
\hline 2 & $65(50)$ \\
\hline 3 & $53(41)$ \\
\hline 4 & $6(5)$ \\
\hline \multicolumn{2}{|c|}{ Presence of metastases* } \\
\hline Yes & $37(28.7)$ \\
\hline No & $92(71.3)$ \\
\hline \multicolumn{2}{|l|}{ Chemotherapy* } \\
\hline Yes & $35(27.1)$ \\
\hline No & 94 (72.9) \\
\hline \multicolumn{2}{|c|}{ Inotrope usage* } \\
\hline Yes & $38(29.5)$ \\
\hline No & $91(70.5)$ \\
\hline \multicolumn{2}{|l|}{ Sepsis * } \\
\hline Yes & $34(26.4)$ \\
\hline No & $95(73.6)$ \\
\hline \multicolumn{2}{|c|}{ Blood transfusion* } \\
\hline Yes & $49(38.0)$ \\
\hline No & $80(62.0)$ \\
\hline \multicolumn{2}{|c|}{ Bricker anastomotic technique* } \\
\hline Yes & $124(96.1)$ \\
\hline No & $5(3.9)$ \\
\hline
\end{tabular}

and 13.3 months. ${ }^{2,3,5-7} \mathrm{~A}$ recent review by Anderson et al determined there was no difference in the rate of ureteroileal anastomotic stricture between open and robotic surgical technique. ${ }^{3}$

Several studies have specifically examined the anastomotic technique for continent urinary diversion and its relation to development of uretero-ileal anastomotic stricture. These showed that an anti-refluxing anastomotic technique

\begin{tabular}{|c|c|c|c|}
\hline Variable & No stricture & Stricture & p value \\
\hline Diabetic & $23(19.3 \%)$ & $7(50.0 \%)$ & 0.014 \\
\hline $\begin{array}{l}\text { High preoperative urea } \\
\text { level (categorized }>7.1 \\
\mathrm{mmol} / \mathrm{L} \text { ) }\end{array}$ & $36(30.3 \%)$ & $9(64.3 \%)$ & 0.016 \\
\hline Smoker & $73(61.3 \%)$ & $12(85.7 \%)$ & 0.091 \\
\hline Male & $86(72.3 \%)$ & $12(85.7 \%)$ & 0.292 \\
\hline Presence of metastases & $33(28.0 \%)$ & $4(36.4 \%)$ & 0.558 \\
\hline $\begin{array}{l}\text { Preoperative hemoglobin } \\
>\text { median } 134 \mathrm{~g} / \mathrm{L}\end{array}$ & $55(46.6 \%)$ & $6(54.6 \%)$ & 0.615 \\
\hline $\begin{array}{l}\text { High preoperative } \\
\text { creatinine level } \\
\text { (categorized }>106 \mu \mathrm{mol} / \mathrm{L} \text { ) }\end{array}$ & $25(21.2 \%)$ & $3(27.3 \%)$ & 0.641 \\
\hline ASA score & & & 0.740 \\
\hline 1 & $5(4.3 \%)$ & 0 & \\
\hline 2 & $60(51.3 \%)$ & $5(41.7 \%)$ & \\
\hline 3 & $46(39.3 \%)$ & $7(58.3 \%)$ & \\
\hline 4 & $6(5.1 \%)$ & 0 & \\
\hline Sepsis & $31(26.3 \%)$ & $3(27.3 \%)$ & 0.943 \\
\hline Chemotherapy & $32(27.1 \%)$ & $3(27.3 \%)$ & 0.991 \\
\hline Age (years) & $70(61-77)$ & $70(64-72)$ & $0.889 *$ \\
\hline Inotrope usage & $35(29.7 \%)$ & $3(27.3 \%)$ & $0.868^{*}$ \\
\hline Preoperative albumin & $34(27-38)$ & $33(26-37)$ & $0.537^{*}$ \\
\hline Body mass index & $28(24-31)$ & $28(24-30)$ & $0.493^{*}$ \\
\hline Blood transfusion & 47 (39.8\%) & $2(18.2 \%)$ & $0.175^{*}$ \\
\hline Operative time (mins) & $270(240-315)$ & $240(180-315)$ & $0.095^{*}$ \\
\hline \multicolumn{4}{|c|}{$\begin{array}{l}\text { Categorical variables written as } n \text { (\% of category), continuous variables written as median } \\
\text { (interquartile range). Percentages do not include patients with missing data. } \\
{ }^{*} \text { Association is away from stricture. }\end{array}$} \\
\hline
\end{tabular}

was associated with an increased risk of uretero-ileal anastomotic stricture..$^{8,9,14}$

When comparing the Wallace and Bricker anastomotic techniques, Liu et al found no significant difference in the rate of uretero-ileal anastomotic stricture. ${ }^{7}$ Evangelidis et al corroborated these results, finding no significant difference between techniques. ${ }^{15}$ Conversely, Kouba et al found a statistically significant higher rate of uretero-ileal anastomotic stricture among those patients undergoing the Bricker compared to Wallace technique, though this should be interpreted with caution due to the fact that those undergoing the Bricker technique had a significantly higher BMI, and it represents the results of a single surgeon. ${ }^{13}$ In our series, the majority of anastomoses were carried out using the Bricker technique and numbers were likely too small in the Wallace technique group to make a useful comparison.

An "anastomotic index" would be beneficial and could be developed based on larger studies and meta-analysis in the future to assign relative risk of uretero-ileal stricture for specific patients. Though the variables that proved significantly associated with increased risk of uretero-ileal anastomotic stricture are largely non-modifiable, identifying those at 


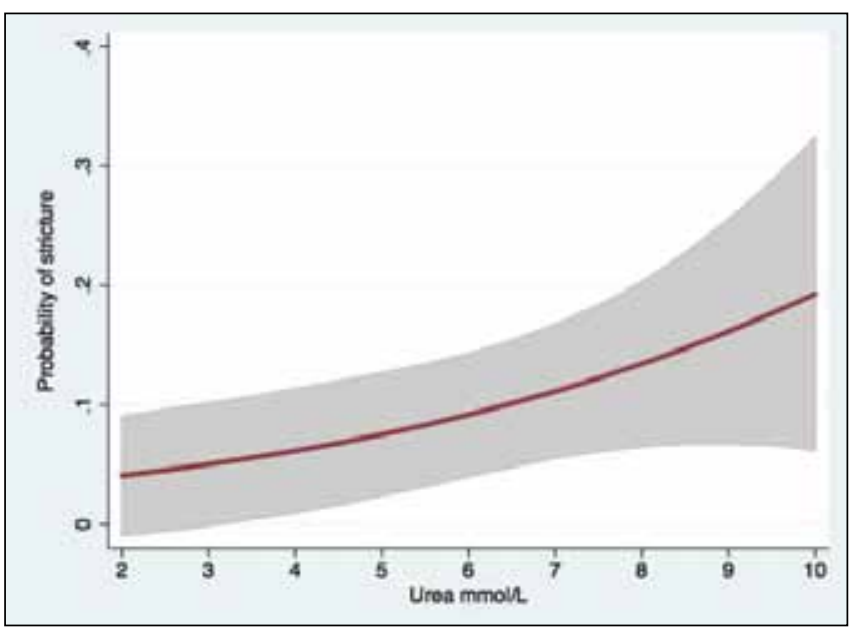

Fig. 1. Predicted probability of uretero-ileal stricture vs. serum urea level. Grey shading indicates $95 \%$ confidence interval.

greater risk may be of benefit. In those patients at higher risk, consideration of an interrupted anastomotic technique in that individual may prove warranted. Further, advocating for avoidance of an anti-refluxing anastomotic technique may be appropriate in this setting.

The finding of diabetes as a risk factor for uretero-ileal stricture could have several possible explanations. It is possible that due to microvascular disease, the distal ureter becomes sensitive to reduced perfusion and is unable to compensate for its relative ischemia. This could, in turn, result in a higher occurrence of stricture. It is also possible that diabetics may undergo more postoperative imagining, leading to increased detection of hydronephrosis and subsequent investigation. Larger series would be required to confirm this.

There are some important limitations to this study that merit mention. Inherent to any retrospective review, the usefulness of the data is limited by the quality of data obtained at the time of collection. This series is limited by patient numbers and also represents the results of a relatively small number of urologists. The urologists responsible for this series often operate in tandem, precluding definitively assigning a particular complication to a specific surgeon. Whether their outcomes can be generalizable to a wider cohort of surgeons remains unknown. Though patient followup was satisfactory, it also remains unknown whether the rate of stricture is accurate due to failure to identify this complication in some. There may also be other variables not examined in this series, which could be risk factors for uretero-ileal stricture, such as preoperative hydronephrosis and other patient and disease factors.

Additionally, without a known biologic explanation as to the reason for elevated urea level predisposing for ureteroileal stricture, the possibility of false discovery exist. It is possible that in those with elevated urea, further imaging tests were obtained leading to a higher rate of stricture detec-

\begin{tabular}{|c|c|c|}
\hline & No stricture (\%) & Stricture (\%) \\
\hline $\begin{array}{l}\text { Non-diabetic, } \\
\text { urea } \leq 7.1 \mathrm{mmol} / \mathrm{L}\end{array}$ & $68(98.6)$ & $1(1.4)$ \\
\hline $\begin{array}{l}\text { One of: diabetic or } \\
\text { urea }>7.1 \mathrm{mmol} / \mathrm{L}\end{array}$ & $43(81.1)$ & $10(18.9)$ \\
\hline $\begin{array}{l}\text { Both diabetic and } \\
\text { urea }>7.1 \mathrm{mmol} / \mathrm{L}\end{array}$ & $8(72.7)$ & $3(27.3)$ \\
\hline
\end{tabular}

tion. We would caution against overstating this finding in a small retrospective series, though further investigation into this phenomenon would be justified.

Uretero-ileal anastomotic stricture remains a significant complication following urinary diversion. With further research, it is hoped that we will be better able to prospectively identify those at highest risk of stricture formation. This will allow urologists to better inform patients of their relative risk, but also to promote taking all possible steps to avoid stricture occurrence.

\section{Conclusion}

In this series, elevated serum urea level $(>7.1 \mathrm{mmol} / \mathrm{L})$ and diabetic patient predict for risk of development of ureteroileal stricture following radical cystectomy and ileal loop. Further study and validation would be warranted.

Competing interests: The authors report no competing personal or financial interests.

This paper has been peer-reviewed.

\section{References}

1. Shabsigh A, Korets R, Vora KC, et al. Defining early morbidity of radical cystectomy for patients with bladder cancer using a standardized reporting methodology. Eur Urol 2009;55:164-76. http://dx.doi. org/10.1016/i.eururo.2008.07.031

2. Schöndorf $D$, Meierhans-Ruf $S$, Kiss $B$, et al. Ureteroileal strictures after urinary diversion with an ileal segment — is there a place for endourological treatment at all? J Urol 2013;190:585-90. http://dx.doi.org/10.1016/i.juro.2013.02.039

3. Anderson $C B$, Morgan $T M$, Kappa $S$, et al. Ureteroenteric anastomotic strictures after radical cystectomy — Does operative approach matter? J Urol 2013;189:541-7. http://dx.doi.org/10.1016/i. juro.2012.09.034

4. Gburek BM, Lieber MM, Blute ML. Comparison of Studer ileal neobladder and ileal conduit urinary diversion with respect to perioperative outcome and late complications. J Urol 1998;160:721-3. http://dx.doi. org/10.1016/50022-5347(01)62767-8

5. Katkoori D, Samavedi S, Adiyat KT, et al. Is the incidence of ureter-intestinal anastomotic stricture increased in patients undergoing radical cystectomy with previous pelvic radiation? BJU Int 2010;105:795-8. http://dx.doi.org/10.1111/j.1464-410X.2009.08835.x

6. Large MC, Cohn JA, Kiriluk KJ, et al. The impact of running vs. interrupted anastomosis on ureterointestinal stricture rate after radical cystectomy. J Urol 2013;190:923-7. http://dx.doi.org/10.1016/i. juro.2013.02.091

7. Liu L, Chen $M$, Li Y, et al. Technique selection of Bricker or Wallace ureteroileal anastomosis in ileal conduit urinary diversion: A strategy based on patient characteristics. Ann Surg Onc 2014;21:2808-12. http:// dx.doi.org/10.1245/s10434-014-3591-z 
Hoag et al.

8. Pantuck AJ, Han KR, Perrotti M, et al. Ureteroenteric anastomosis in continent urinary diversion: Long-term results and complications of direct vs. non-refluxing techniques. J Urol 2000;163:450-5. http://dx.doi. org/10.1016/S0022-5347(05)67898-6

9. Studer UE, Burkhard $\mathrm{FC}$, Schumacher $M$, et al. Twenty years' experience with an ileal orthotopic low pressure bladder substitute — lessons to be learned. J Urol 2006;176:161-6. http://dx.doi.org/10.1016/ S0022-5347(06)00573-8

10. Tal R, Sivan B, Kedar D, et al. Management of benign ureteral strictures following radical cystectomy and urinary diversion for bladder cancer. J Urol 2007;178:538-42. http://dx.doi.org/10.1016/i. juro.2007.03.142

11. Richards KA, Cohn JA, Large MC, et al. The effect of length of ureteral resection on benign ureterointestinal stricture rate in ileal conduit or ileal neobladder urinary diversion following radical cystectomy. Urol Oncol 2015;33:el-8. http://dx.doi.org/10.1016/j.urolonc.2014.05.015

12. DiMarco DS, LeRoy AJ, Thieling $S$, et al. Long-term results of treatment for ureteroenteric strictures. Urology 2001;58:909-13. http://dx.doi.org/10.1016/50090-4295(01)01420-0
13. Kouba $E$, Sands $M$, Lentz $A$, et al. A comparison of the Bricker vs. Wallace ureteroileal anastomosis in patients undergoing urinary diversion for bladder cancer. J Urol 2007;178:945-8. http://dx.doi. org/10.1016/i.juro.2007.05.030

14. Hautman RE, de Petriconi RC, Volkmer BG. 25 Years of experience with 1000 neobladders: Long-term complications. J Urol 2011;185:2207-12. http://dx.doi.org/10.1016/i.juro.2011.02.006

15. Evangelidis $A$, Lee EK, Karellas ME, et al. Evaluation of ureterointestinal anastomosis: Wallace vs. Bricker. J Urol 2006; 175:1755-8. http://dx.doi.org/10.1016/S0022-5347(05)01020-7

Correspondence: Dr. Nathan Hoag, Department of Urology, Austin Hospital, University of Melbourne, Australia; nathan.hoag@viha.ca 